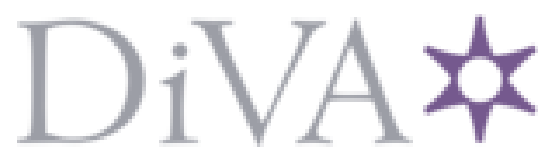

http://www.diva-portal.org

This is the published version of a paper presented at Railways 2016.

Citation for the original published paper:

Cha, Y. (2016)

On Particulate Emissions from Individual Trains in Tunnel Environments.

In: Proceedings of the Third International Conference on Railway Technology: Research,

Development and Maintenance, Sardinia, Italy 5-8 April 2016 Dun Eaglais, Kippen Stirlingshire,

FK8 3DY, UK

N.B. When citing this work, cite the original published paper.

Permanent link to this version:

http://urn.kb.se/resolve?urn=urn:nbn:se:kth:diva- 185507 


\title{
Paper 1
}

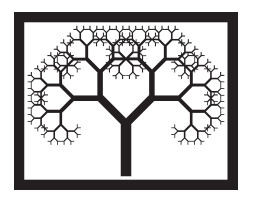

(C) Civil-Comp Press, 2016

Proceedings of the Third International Conference on

Railway Technology: Research, Development and

Maintenance, J. Pombo, (Editor),

Civil-Comp Press, Stirlingshire, Scotland, paper 1, 2016.

\section{On Particulate Emissions from Individual Trains in Tunnel Environments}

\author{
Y. Cha ${ }^{1}$, U. Olofsson ${ }^{1}$, M. Gustafsson ${ }^{2}$ and C. Johansson ${ }^{3}$ \\ ${ }^{1}$ Department of Machine Design, KTH Royal Institute of Technology, Stockholm, Sweden \\ ${ }^{2}$ VTI The Swedish National Road and Transport Research Institute, Linköping, Sweden \\ ${ }^{3}$ SLB Analys, Technical Department, Stockholm, Sweden
}

Keywords: airborne particulates, individual train, particulate concentration, size distribution, tunnel environment, principal component analysis.

In order to detect the concentrations and size distributions of airborne particles that were generated by individual moving trains on an underground railway platform, a series of realtime measurements were undertaken. The measurement range covered the ultrafine (less than $100 \mathrm{~nm})$ and partly the fine $(100 \mathrm{~nm}$ to $2.5 \mu \mathrm{m})$, but not the coarse fraction $(2.5$ to $10 \mu \mathrm{m})$. The results show that the individual trains with stop and start at the platform elevate substantially the particulate number concentrations with a diameter size greater than $100 \mathrm{~nm}$. Two size modes of the particulate number concentrations are obtained. One mode peaks around $170 \mathrm{~nm}$ when a train stopped/started, while the other is around $30 \mathrm{~nm}$ when no train operated in the station. By using principal component analysis, four components are extracted from the thirty two-analyzed particulate sizes, indicating four different contributors in those detected particles. It is revealed from this study that the particulate matter released by individual moving trains (mainly through mechanical wear and turbulent resuspension) is a key contributing source of the fine particles on underground railway platforms, which can be separated from the background by their different size distributions. 